\title{
Prevalence of Human Papilloma Virus Sub Genotypes following Head and Neck Squamous Cell Carcinomas in Asian Continent, A Systematic Review Article
}

\author{
Naeem Bukhari' ${ }^{1 *}$, Joe P Joseph ${ }^{2}$, Sayed Sajid Hussain ${ }^{3}$, Muhammad Adeeb \\ Khan $^{4}$, Marcel Jose Yibirin Wakim ${ }^{5}$, Esam Bashir Yahya ${ }^{6}$, Amina Arif ${ }^{7}$, Afshan \\ Saleem $^{8}$, Nadeem Sharif ${ }^{9}$
}

\begin{abstract}
Objectives: In current era of blue brain intelligence and technology access at ease, standardization of disease etiology demands extensive research to drop-down human papilloma virus associated head and neck squamous cell carcinomas impact at large. Present retrospection aims to estimate comparative association of human papilloma virus sub-genotypes in head and neck squamous cell carcinomas, critical analysis of existing research gap, treatment progress, co-infection, gender association, national status and challenges following Human papilloma virus led head and neck squamous cell carcinomas among world largest continent. Background: Head and neck squamous cell carcinomas are not just like malignancies of uterine cervix, lymph nodes and breast cancers. Human papilloma virus led head and neck squamous cell carcinomas treatment directly impact Central nervous system in humans. Intriguingly, human papilloma virus mediated immune response increases patient survival, which indirectly transmit human papilloma virus in future generations and act as a potential threat developing neurogenic disorders. Methods: An objective based search strategy, following comprehensive and specific search approaches were made to retrieve recent 12 years research data from five different NCBI databases. Out of 300 shortlisted articles, only 24 principal studies met the inclusion criteria. Results: Highest human papilloma virus prevalence (10.42 \%) was found in South Asia, $5.8 \%$ in South East Asia, $5.7 \%$ East Asia, $2.5 \%$ in west Asia and no relevant updated data was found from central Asian continent. Highest prevalence (10\%) of HPV genotype-16 was recorded in Asia among 3, 710 enrolled cases including 2201 males, 1149 females and 360 cases of unknown gender. While undifferentiated multiple HPV genotype prevalence was $5.5 \%$ (204 cases). Lowest percentage of HPV sub-types 68, 72, 57, 39 were recorded respectively. Pakistan ranked top reporting highest number of HPV-16 cases, Taiwan HPV-18, India HPV-31, Japan HPV-35 and Singapore in HPV-16 and HPV-18 co-infection rates respectively. Conclusions: Exact prevalence of HPV associated head and neck squamous cell carcinomas among Asian population is still debatable. Due to higher heterogeneity $(\mathrm{P}<0.00001), \mathrm{I}^{2}=81-88 \%$ at $95 \%$ confidence interval), non-availability and limitations of reported studies from Asian sub-continents especially central Asia, western Asia and from south and south east Asia demand large scale collaborative research culture to standardize head and neck squamous cell carcinomas aetiology.
\end{abstract}

Keywords: HPV, HNSCC, South Asia, Central Asia, Middle East

Asian Pac J Cancer Prev, 20 (11), 3269-3277

\section{Introduction}

Classically HPV led squamous cell carcinomas of head and neck arise from oropharynx impacting multiple sites including, lip, tongue, eye, chin and nasopharynx as well (Syrjanen et al., 1983). Globally HNSCCs are the sixth most common deadly malignancies, causing
350,000 deaths each year with annual incidence of 600,000 reported cases (Ferlay et al., 2010). While, study of National statistics office in United Kingdom reported 7,745 cases each year (Office for National Statistics, 2009). Specifically, Oropharyngeal and tongue malignancies are predominant cancers in west. However, in general HNSCC a heterogenous group of tumours are

${ }^{1}$ Centre for Human Genetics, Hazara University Mansehra, ${ }^{4}$ Department of Zoology, Women University of Azad Jammu and Kashmir, Bagh, ${ }^{7}$ Faculty of Life Sciences, University of Central Punjab, ${ }^{8}$ Department of Microbiology, ${ }^{9}$ Department of Medical Laboratory Technology, University of Haripur, Pakistan, ${ }^{2}$ Department of Physiology and Biophysics, Case Western Reserve University School of Medicine, USA, ${ }^{3}$ Department of Food Science and Engineering, University of Technology PR China, ${ }^{5}$ Internal Medicine Department, Central University of Venezuela, Venezuela, ${ }^{6}$ Department of Microbiology, Faculty of Science, Al Asmarya Islamic University, Zliten, Libya.*For Correspondence: naeembukhari20@gmail.com 
shortly reported from South Asia instead of entire Asian continent (Bhurgri et al., 2006). According to Faheem A et al study in 2009, HNSCC is considered second most prevalent type of cancer in Pakistani subjects alone with recorded incidence of $40.1 \%$ (Bhurgri et al., 2006; Faheem et al., 2009). Commencing comparative clinical aetiology of HNSCCs from Europe based case control studies. About (70-75\%) HNSCCs cases are synergistically associated with tobacco and alcohol consumption accompanied by familial history (Hashibe et al., 2009; McKay et al., 2011). Whereas, (10-15\%) HNSSCs cases are associated with decreased intake of fruit and vegetables (Chuang et al., 2012; De Feo et al., 2008). In contrast to European countries, betel-quid chewing also plays a major role in the development of malignant tumours focusing Asian subjects (Chen et al., 2008). Molecular biology of Head and neck carcinomas revealed that genetic mutations and chromosomal abnormalities, especially mutation of p53 gene involvement in development of head and neck cancers (Leemans et al., 2011). Recent progression in research trends indicated decline in alcohol and tobacco induced HNSCCs. Whereases, Prevalence of HPV induced HNSCCs is increasing. Another supporting evidence suggest higher chances of HPV transmission during sexual behaviour in comparison to tobacco and alcohol consumption (Chaturvedi et al., 2011; Gillison., et al 2012). Instead of HPV-genotypes independently, co-infection with Epstein Barr virus also errand development of nasopharyngeal carcinomas (Termine et al., 2008). Classical research reported $95 \%$ prevalence of HPV in cervical carcinomas and 12.8\%-59.9\% association of HPV-Subtypes in HNSCCs, including HPV-35, HPV-33, HPV-31, HPV-18 and HPV-16. Which clearly highlights existing research gap focusing HPV subtype specific prevalence and exact role following HNSCCs (Syrjanen et al., 1983; zur et al., 2009; Westra et al., 2009; Liebertz et al., 2010; Nasman et al., 2009; Ha et al., 2009). HPV led HNSCCs require progressive and meticulous treatment measures. After critical care and monitoring only five-year survival rate of $68 \%$ was possibly achieved yet. While delayed tumour detection and improper treatment may impact nervous system in humans. Intriguingly, HPV mediated immune response increases patient survival, which indirectly transmit HPV in future generations and act as a potential threat developing neurogenic disorders (Pai et al., 2009; Howlader et al., 2009).

Present retrospection aims to estimate comparative association of HPV sub-genotypes in head and neck squamous cell carcinomas among world largest continent. The main objectives include to critically analyse existing research gap, epigenetic treatment progress, multiple genotype co-infection, gender association, national status and challenges following HPV related head and neck squamous cell carcinomas among Asian people.

\section{Materials and Methods}

\section{Database search strategy}

An objective based search strategy, following comprehensive and specific search approaches to retrieve recent 12.5-year research data from five different NCBI databases including PubMed, MeSH, PubMed Central, NLM Catalog and Bookshelf.

\section{Inclusion and exclusion Criteria}

The articles published in English language focusing human subject only were considered. Criteria followed include recent 12.5-year studies reported from five different geographic regions of Asia. Studies who had significantly explained the role of any sub-genotype of HPV in head and neck cancer. While, studies contradicting above mentioned inclusion criteria were considered ineligible and excluded. Detailed inclusion and exclusion criteria are mentioned in Table 1.

\section{Studies Selection}

By Specific approach overall, Principal author and third co-author shortlisted $n=300$ abstracts from NCBI databases, including $\mathrm{n}=236$ duplicate and older than Jan-2009 were excluded for further analysis. From above mentioned 300 citations, only 64 full text articles were found. But, Due to irrelevance with inclusion criteria 40 full text articles were excluded. However, 24 principal studies were focussed and critically analyzed Table 2 .

\section{Data Retrieval and Risk Measures}

Two co-investigators belonging from another country focused on data review and validation in collaboration with principal author for each included study. Country of study, first author, year of publication, type/site of lesion, number of cases included. Specific HPV type and overall prevalence of HPV in head and neck cancer infection was also studied. Prevalence estimation was done as total number of patient positive for specific HPV-subtype divided by total number of HNSCC patients. The accuracy of data search was counter checked by a second researcher, Further, Omissions; errors were resolved by sharing it with another co-investigator from another territory.

\section{Statistical Analysis}

Statistical analysis was done by using Revman 5.30, Prisma and Microsoft Excel 2010 multiple tools.

\section{Characteristics of Meta-Analysis}

Meta-analysis concentrating number of included studies from a country, patient selection, mean age, method followed, and relative outcomes as described in (Table 3) from 24 eligible studies. Khovidhunkit et al., (2008) reported only one patient with non-specific HPV out of 65 oral squamous cell carcinomas cases. Luo et al., (2007) examined 51 oral squamous cell carcinoma biopsies and reported $25 \%$ high risk HPV positive cases. HPV-16 and HPV-18 were more prevalent than HPV-33 and HPV-52. Similar study carried by Li-Ang Lee et al., in (2012) reported increasing trend of high-risk HPV in Taiwan. Akhtar et al., (2013) examined 34 oral squamous cell carcinoma confirmed patients. author followed PCR method for detection of HPV subtypes highlighting no one person was affected by any specific high-risk HPV type among Bengali patients. Zhang et al., (2006) highlighted HPV association in oral squamous cell carcinomas including high risk HPV-16 and HPV-18 were positive 
among 18 patients out of total 63 confirmed cases. In 2012 two similar studies were carried out, one on healthy patient saliva and other on Oral squamous cell carcinomas patients reported $6.1 \%$ and $3.9 \%$ high HPV-6, HPV-18, HPV-66 and HPV-16, HPV-18, HPV-33, HPV-57 respectively (Hafed et al., 2012; Seifi et al., 2013). Another past study carried by Kermani I et al in 2012 reported 42.8\% patients with high risk HPV-16 and HPV-18. He examined fourteen different Oro-pharyngeal, hypo-pharyngeal and laryngeal carcinoma patients. Maruyama $\mathrm{H}$ et al., 2014 reported $34.4 \%$ specific type HPV 16, 18, 33, 35, 58 respectively among 163 confirmed patients of oropharynx. A recent study reported $20.4 \%$ high risk HPV-16 among 206 oral squamous cell carcinomas patients (Kerishnan et al., 2016). Baig et al., (2012) reported 47 HPV patients with high risk HPV-16 and HPV-18. They examined oral submucosal tissues from 262 Gutkka addict persons and HPV was present in $20 \%$ patients. Na-Kyung Ryoo et al., 2013 tested 54 patients of retinoblastoma, found all patients were HPV negative. Another same country study conducted by Lee et al., (2010) on oral tongue lesions reported $36 \%$ non-specific HPV positive cases. Their Data showed 13 patients were HPV positive. Gunasekera et al., (2015) reported 46\% high risk HPV-16 and HPV-18. Total 78 oropharyngeal carcinoma biopsies were included in study. In total 65 laryngeal and hypo-laryngeal carcinoma for high risk HPV-16. Only 27 (41.5\%) samples were positive for HPV-16. Two studies conducted by Hafed et al., (2012) and Mansour et al., (2012) reported that high risk HPV-16 and HPV-18 were $23.52 \%$ and $86 \%$ respectively in tumour samples. Due to limited number of
Burden of HPV-Subtypes Associated HNSCC in Asian Continent

studies and underdeveloped infrastructure only one recent study conducted by Jalouli et al., (2012) reported that 20\% HPV were positive in oral squamous cell carcinomas.

\section{Results}

Based on purely two objective based search strategies including comprehensive and specific quality data retrieval approaches. overall 56,302 search results, 10,999 were reported from south Asia, 2,346 from middle East, 1,710 from central Asia, 1,229 from East Asia and only 17 search results from western Asia were found from recent eleven year published sources (Table 4). Our specific approach was based upon shortlisting relevant studies reported from each of five Asian regions.

Reflecting 24 principal studies, overall (9\%) prevalence of HPV was recorded in South Asia, $5.04 \%$ in South East Asia,4.93 \% East Asia, $2.21 \%$ in west Asia, $0.32 \%$ from a bilateral Pak-Chinese study and no relevant updated patients' data was found from central Asian continent regarding HNSCC. From comparative point of regional HPV prevalence, highest prevalence of HPV was noted in south Asia, south East Asia and very less in central and west parts of Asian continent respectively (Figure 1).

\section{HPV-genotype Specific Prevalence}

Overall highest prevalence (10.08\%) of HPV sub-genotype-16 was recorded in Asia among 3, 710 enrolled cases including 2,201 males, 1,149 females and 360 cases of unknown gender. While multiple HPV genotype prevalence was $5.5 \%$ (204 cases), HPV-18

\section{Prevalance of HPV associted HNSCC in Asian Continents}

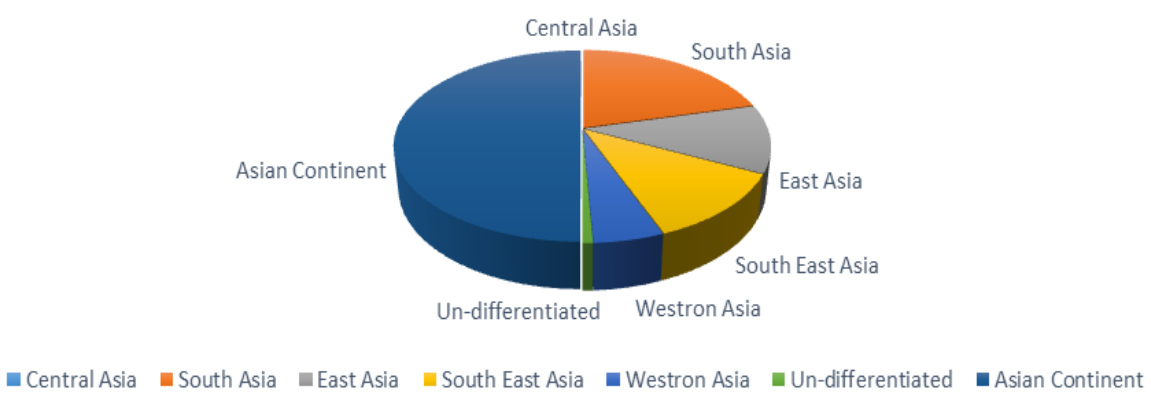

Figure 1. Comparative Analysis of HPV Distribution in Asian Continent

Table 1. Detailed Inclusion and Exclusion Criteria

\begin{tabular}{ll}
\hline Inclusion Criteria & \multicolumn{1}{c}{ Exclusion criteria } \\
\hline Original Studies focusing HPV as ethology in HNC & $\begin{array}{l}\text { Studies followed other than HPV role in HNC like, HPV role in } \\
\text { cervical cancer }\end{array}$ \\
$\begin{array}{l}\text { Studies reported from Central Asia, Middle East, East Asia, } \\
\text { South Asia and western Asia. }\end{array}$ & $\begin{array}{l}\text { Studies reported from other then Asian geographic regions } \\
\text { Review articles, case reports, letter to the editor and short } \\
\text { communication }\end{array}$ \\
Articles written in English language & $\begin{array}{l}\text { Studies published in Other than English language } \\
\text { Articles who focused human subjects }\end{array}$ \\
Patients irrespective of age and gender & $\begin{array}{l}\text { Studies reporting no relevant age and gender associated } \\
\text { information. }\end{array}$ \\
Studies reported till $30^{\text {th }}$ August 2019. & Studies published before $1^{\text {st }}$ Jan 2007. \\
\hline
\end{tabular}


Table 2. Comprehensive Studies Selection Protocol Following Five Different Databases by Prisma.

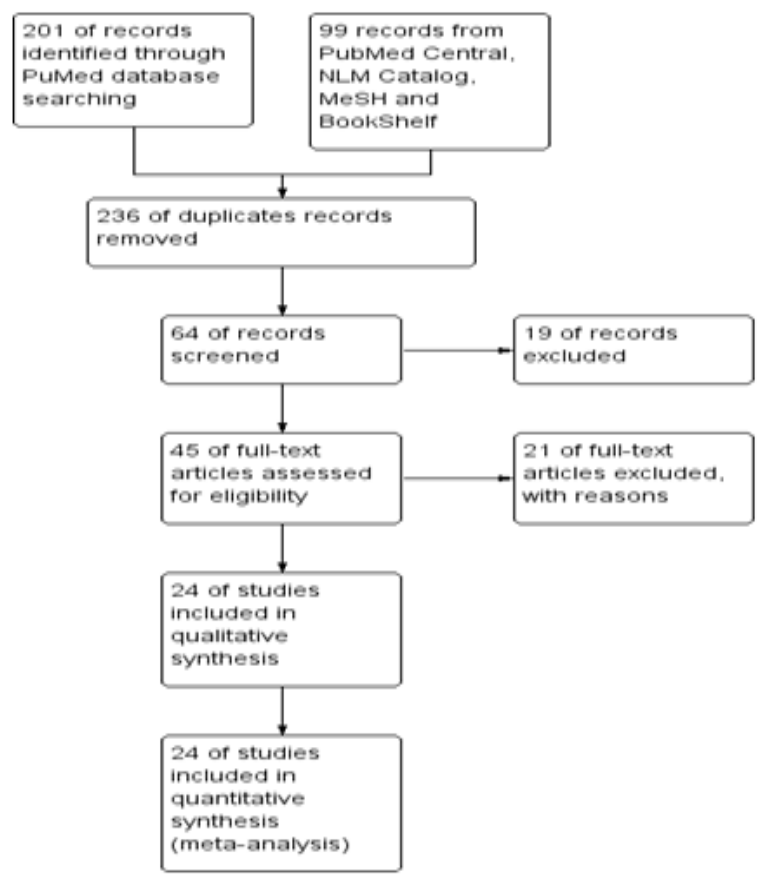

(2.12\%), HPV-16 and 18 co-infection (1.51\%) and $1.3 \%$ cases were not known for any type specific HPV-genotype following whole Asian continent. Lowest percentage of HPV sub-genotypes 68, 72, 57, 39 were recorded respectively (Table 5).
Assessment of risk bias and clinical heterogeneity

By following dichotomous data analysis random effect model at $95 \%$ CI. A significant clinical heterogeneity $\left(\mathrm{Tau}^{2}=1.14, \mathrm{P}<0.00001, \mathrm{I}^{2}=87 \%\right)$ was found between HPV positive HNSCCs and type specific HPV-16 led HNSCCs in Asian continent with an overall Odd ratio $=3.41$. (Figure $2 \mathrm{~A})$. Whereas, type specific HPV-18 clinical heterogeneity $\left(\mathrm{Tau}^{2}=1.87, \mathrm{P}<0.00001\right.$, $\mathrm{I}^{2}=81 \%$ ) with an Odd ratio of $=14.57$ (Figure 2B). clinical heterogeneity following HPV co-genotype 16-18 in HNSCCs and HPV multi-genotype led HNSCCs ( $\mathrm{Tau}^{2}$ $=5.43, \mathrm{P}<0.00001, \mathrm{I}^{2}=85 \%$ ) with an Odd ratio $=0.47$ (Figure 2C). Comparing HPV-16 positive and HPV-18 positive genotype prevalence a significant heterogeneity was calculated $\left(\mathrm{Tau}^{2}=3.52, \mathrm{P}<0.00001, \mathrm{I}^{2}=88 \%\right)$. Greater heterogeneity in methodological aspect of included studies was also observed. Due to variable genotype testing methods including, PCR primers, ELIZA kits, ISH protocols and diversity in detection of HPV sub-genotypes followed by each individual study (Table 3 ). In parallel to determine the level of heterogeneity in our meta-analysis, we followed random effect model to estimate clear HPV type specific genotype prevalence in Asian continent (Table 5A- Table 5D).

The highest heterogeneity $\left(\mathrm{Tau}^{2}=10.70, \mathrm{P}<0.00001\right.$, $\left.\mathrm{I}^{2}=89 \%, \mathrm{z}=5.09\right)$ was observed in overall $798 \mathrm{HPV}$ positive cases in comparison to 48 non-determined HPV genotype case groups (Figure 2E).

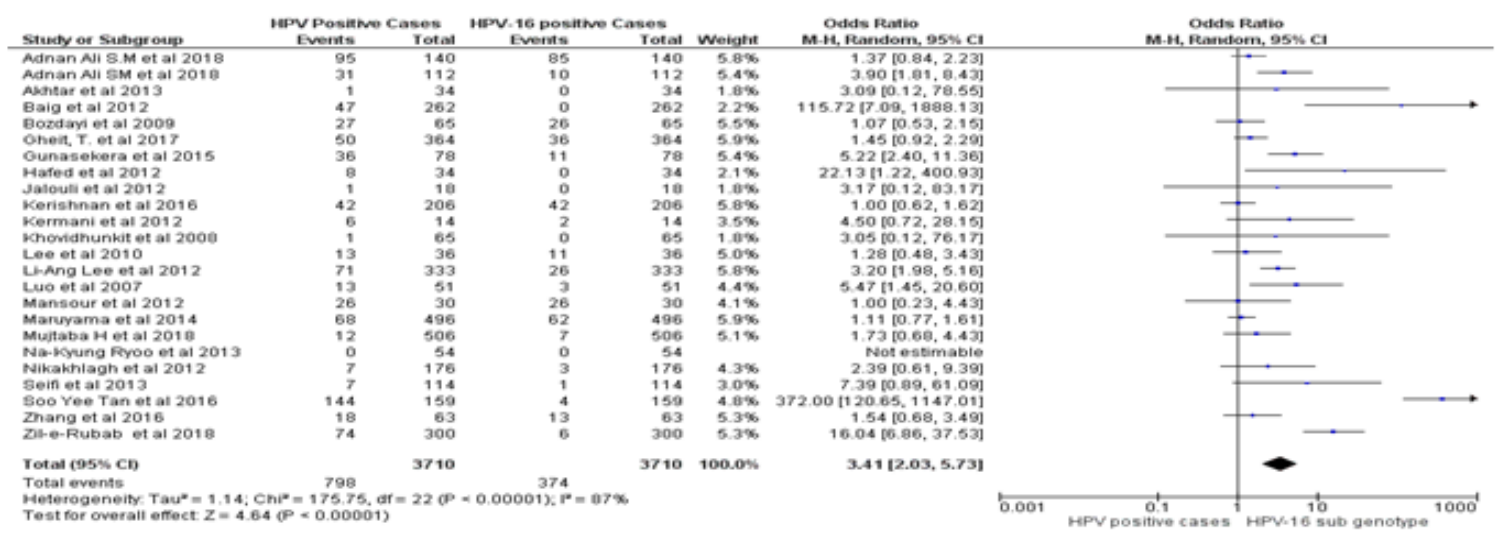

Figure 2A. Forest Plot of Comparison, HPV Positive in HNSCCs and Type Specific HPV-16 Led HNSCCs.

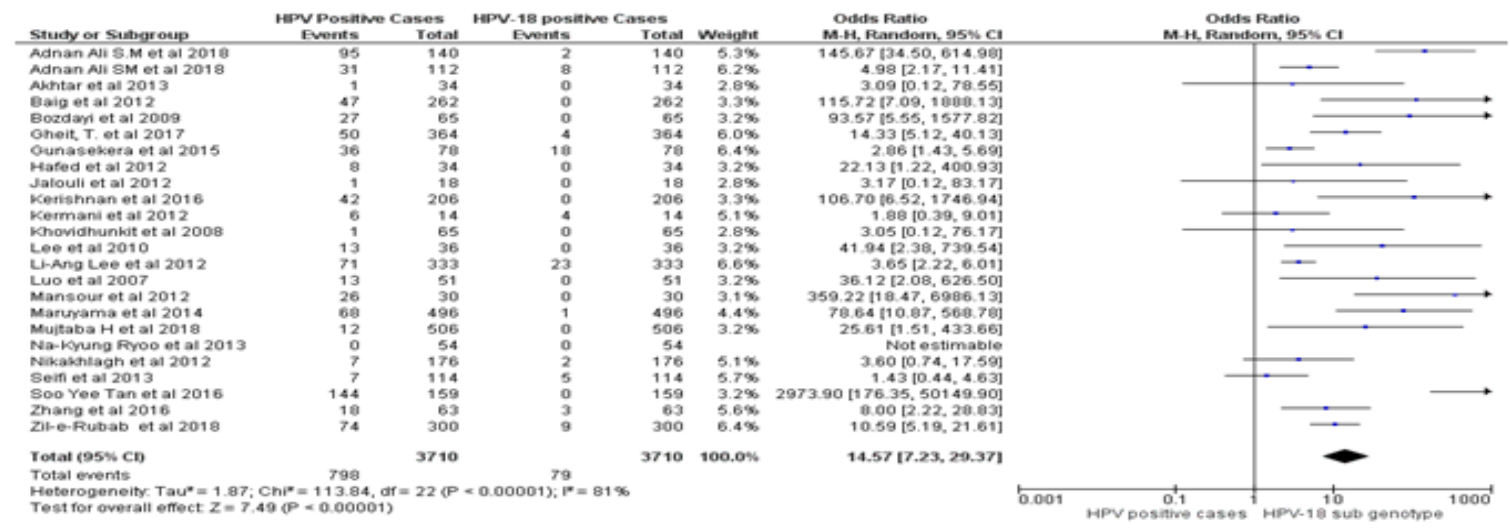

Figure 2B. Forest Plot of Comparison, HPV Positive in HNSCCs and Type Specific HPV-18 Led HNSCC 


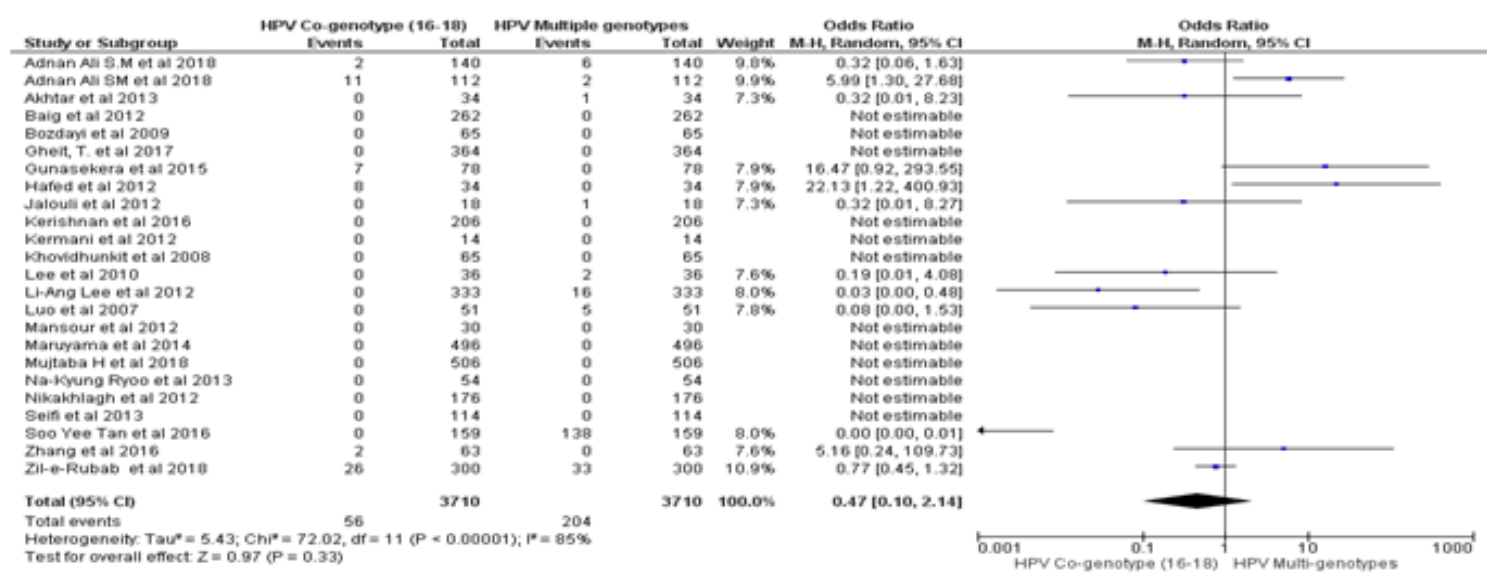

Figure 2C. Forest Plot of Comparison, HPV Positive in HNSCCs and Multi -HPV Genotype Led HNSCCs

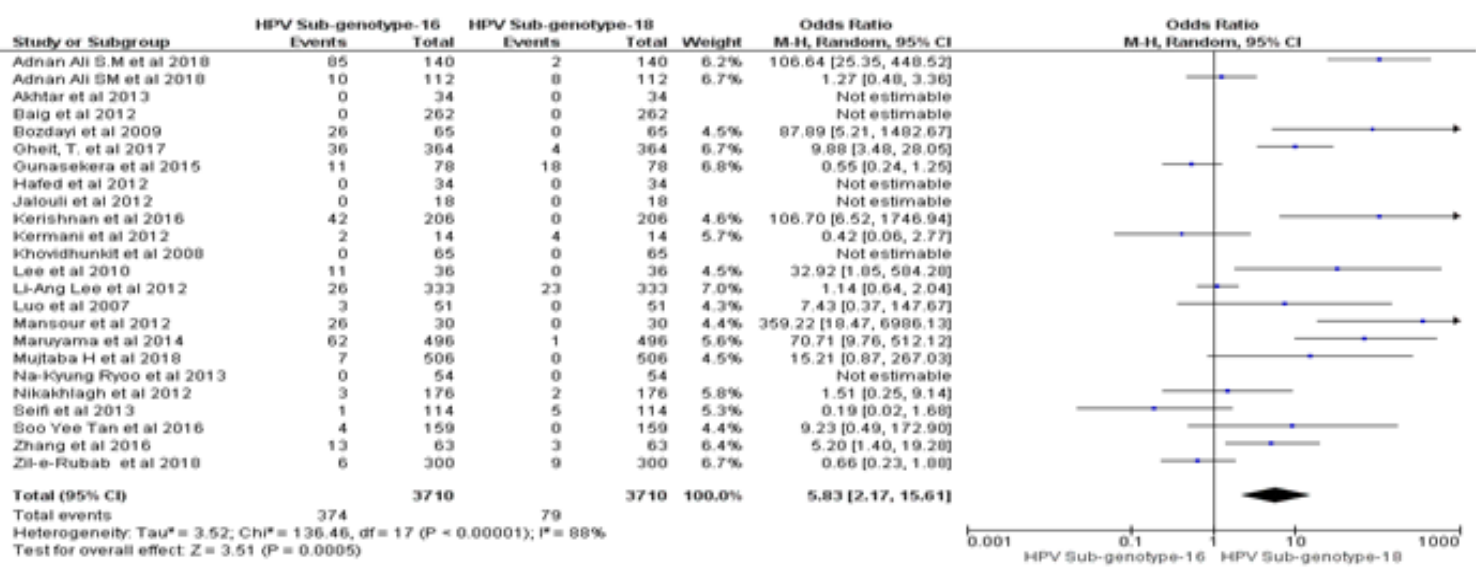

Figure 2D. Forest Plot of Comparison, HPV-16 Positive in HNSCCs and HPV-18 Genotype Led HNSCCs

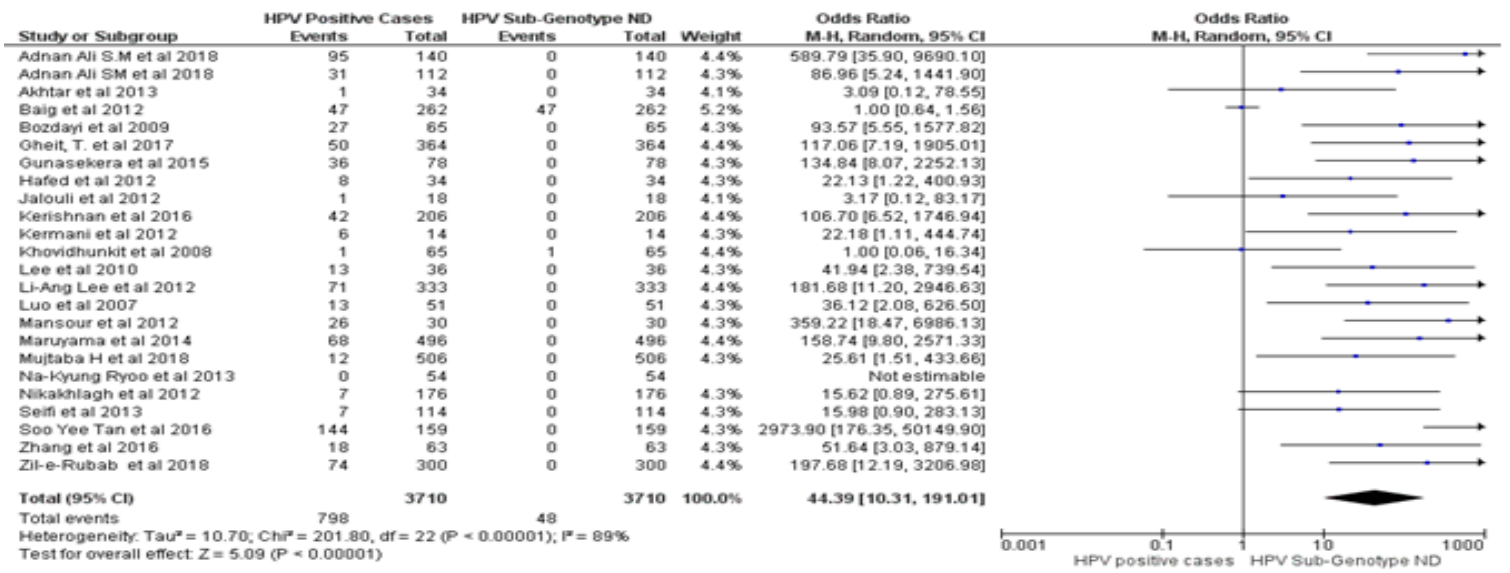

Figure 2E. Forest Plot of Comparison, Positive in HNSCCs Cases and HPV-ND Genotype Led HNSCCs

HPV Sub-genotypes regional prevalence trends

South Asia

In south Asia HPV specific genotype HPV-16, HPV-18, HPV-16,18 in combination and multiple HPV genotype were most prevalent $4 \%, 1.11 \%$ and $1.24 \%$ and $1.13 \%$ respectively. Pakistan ranked top reporting highest prevalence $(2.72 \%)$ of HPV-16 and India in HPV-31(0.61\%), (Table 2).

\section{South East Asia}

HPV was (5.04\%) prevalent in south East Asia. However, $3.72 \%$ multiple HPV genotypes were only reported from Singapore and overall HPV-16 was (1.24\%) prevalent in South East Asia (Table 2).

\section{East Asia}

In total 1,033 (27.84\%) cases reported from east Asia HPV was found in $183(4.93 \%)$ cases including (3.10\%) HPV-16, 0.37\% HPV-18, 0.03\% HPV-33, HPV-39, HPV-58, HPV-66 and HPV-72 respectively. While $0.62 \%$ cases were affected with multiple HPV genotypes. Taiwan was on top reporting $(0.6 \%)$ prevalence of HPV-18 and in Japan HPV-35 was $(0.08 \%)$ prevalent (Table 2). 
Table 3. Characteristics of in Studies Included in Meta-analysis

\begin{tabular}{|c|c|c|c|c|c|c|c|c|c|c|}
\hline Country & Study conducted & Year & $\begin{array}{l}\text { No of } \\
\text { positive } \\
\text { cases }\end{array}$ & Total & Male & Female & Unknown & $\begin{array}{l}\text { Mean } \\
\text { Age Y }\end{array}$ & Method & Outcomes \\
\hline Pakistan & Baig et al & 2012 & 47 & 262 & 42 & 220 & 0 & 27 & PCR & ND \\
\hline Pakistan & Adnan Ali SM et al & 2018 & 95 & 140 & 82 & 58 & 0 & 40 & PCR & 16,18 \\
\hline Pakistan & Adnan Ali SM et al & 2018 & 31 & 112 & 76 & 36 & 0 & 47.8 & PCR & 16,18 , both \\
\hline Pakistan & Zil-e-Rubab et al & 2018 & 74 & 300 & 210 & 90 & 0 & 36 & PCR & 16,18 \\
\hline India & Gheit, T. et al & 2017 & 50 & 364 & 263 & 101 & 0 & 53.6 & PCR & $16,18,31,35,56$ \\
\hline Singapore & Soo Yee Tan et al & 2016 & 144 & 159 & 0 & 0 & 159 & 60.7 & PCR & $16,18,31,45,56,68$ \\
\hline China, Pakistan & Mujtaba $\mathrm{H}$ et al & 2018 & 12 & 506 & 305 & 201 & 0 & 19 & PCR & $6,11,16,58$ \\
\hline Thailand & Khovidhunkit et al & 2008 & 1 & 65 & 15 & 50 & 0 & 0 & 0 & 0 \\
\hline Taiwan & Luo et al & 2007 & 13 & 51 & 48 & 3 & 0 & 55 & PCR & $16,18,33,52$ \\
\hline Taiwan & Li-Ang Lee et al & 2012 & 71 & 333 & 316 & 17 & 0 & 51 & PCR & $16,18,52$ \\
\hline Iran & Seifi et al & 2013 & 7 & 114 & 52 & 53 & 9 & 31.6 & PCR & $6,18,66$ \\
\hline Iran & Nikakhlagh et al & 2012 & 7 & 176 & 151 & 25 & 0 & 67 & PCR & $16,18,33,57$ \\
\hline Iran & Kermani et al & 2012 & 6 & 14 & 6 & 8 & 0 & 39.7 & PCR & 16,18 \\
\hline South Korea & Na-Kyung Ryoo et al & 2013 & 0 & 54 & 0 & 0 & 54 & 2 & ISH & ND \\
\hline South Korea & Lee et al & 2010 & 13 & 36 & 0 & 0 & 36 & 0 & PCR & ND \\
\hline Egypt & Hafed et al & 2012 & 8 & 34 & 12 & 22 & 0 & 56 & $\mathrm{IHC}$ & 16,18 \\
\hline Egypt & Mansour et al & 2012 & 26 & 30 & 15 & 15 & 0 & 52.9 & PCR & 16 \\
\hline Bangladesh & Akhtar et al & 2013 & 1 & 34 & 0 & 0 & 34 & 0 & PCR, IHC, ISH & ND \\
\hline China & Zhang et al & 2016 & 18 & 63 & 25 & 38 & 0 & 56 & PCR & 16,18 \\
\hline Japan & Maruyama et al & 2014 & 68 & 496 & 380 & 66 & 50 & 65 & PCR & $16,18,33,35,58$ \\
\hline Malaysia & Kerishnan et al & 2016 & 42 & 206 & 68 & 138 & 0 & 48.9 & PCR & 16 \\
\hline Sri Lanka & Gunasekera et al & 2015 & 36 & 78 & 73 & 5 & 0 & 0 & ELIZA & 16,18 \\
\hline Turkey & Bozdayi et al & 2009 & 27 & 65 & 62 & 3 & 0 & 58 & ND & 16 \\
\hline Yemen & Jalouli et al & 2012 & 1 & 18 & 0 & 0 & 18 & 61.5 & PCR & ND \\
\hline
\end{tabular}

ND, not determined.

Table 4. Comprehensive and Specific Data Retrieval Outcomes

\begin{tabular}{llcccccc}
\hline No & Search Terms & \multicolumn{3}{c}{ Different Database Search Results } & \multicolumn{2}{c}{ Overall Results } \\
& & PubMed & MeSH & PubMed Central & NLM Catalog & Book Shelf \\
\hline 1 & HNSCC in Asia & 704 & 0 & 4,062 & 6 & 84 & 4,856 \\
2 & HPV in HNSCC & 2,753 & 0 & 8,614 & 3 & 147 & 11,517 \\
3 & HPV subtypes in HNSCC & 101 & 0 & 2,037 & 0 & 30 & 2,168 \\
4 & HNSCC aetiology & 66 & 0 & 1,640 & 0 & 41 & 1,747 \\
5 & HPV vaccination & 7,000 & 0 & 11,910 & 30 & 0 & 173 \\
6 & HPV in Central Asia & 54 & 0 & 1,573 & 03 & 1,710 \\
7 & HPV in East Asia & 58 & 0 & 1,124 & 0 & 47 & 1,229 \\
8 & HPV in South Asia & 89 & 0 & 10,908 & 2 & 0 & 10,999 \\
9 & HPV in Weston Asia & 0 & 0 & 17 & 0 & 0 & 17 \\
10 & HPV in Middle East & 422 & 0 & 1,850 & 0 & 74 & 2,346 \\
\hline
\end{tabular}

\section{West Asia}

In western Asia 2.21\% prevalence of HPV was estimated. Similarly, HPV-16 and HPV-18 genotypes were found most prevalent. Equal prevalence of HPV-16 was obtained from both Egypt and Turkey (Table 2).

\section{Un-Categorized group}

A collaborative study conducted by Mujtaba et al., (2018) enrolled 506 HNSCC patients both from china and Pakistan. HPV was prevalent in 12 cases $(0.32 \%)$. Inclusion of Mujtaba et al., (2018) in a distinct category was done to highlight recent progress in collaborative research culture as well (Table 2).

\section{Central Asia}

Unfortunately, as per criteria set forth, not a single study from central Asian territories were found including Turkmenistan, Kazakhstan, Kyrgyzstan, Uzbekistan and Tajikistan. 


\section{Discussion}

First time our review critically analyzed the available literature covering the whole Asian continent and reported $21.5 \%$ prevalence of HPV associated HNSCCs with clear heterogeneity insights. While prior to current study HPV association in HNSCCs was considered in the range of 12.8\%-59.9 \%, including HPV-35, HPV-33, HPV-31, HPV-18 and HPV-16 genotypes only. (zur et al., 2009; Westra et al., 2009; Liebertz et al., 2010; Nasman et al., 2009). However, our review was a collaborative research effort to minimize cancer research gap in Asian continent and focussed prevalence of more than fifteen HPV sub-genotypes. Similar large scale regional and worldwide studies covering whole Asia reported (33\%) HPV prevalence in HNC-subsite (Oral cavity) among Asians, $16 \%$ in European and 16. 1\% North American populations respectively (Kreimer et al., 2005) In 2014 another review reported by Abogunrin $\mathrm{S}$ et al focusing European population estimated $40 \%$ prevalence of HPV in head and neck carcinomas. We accept exact prevalence of HPV associated HNSCCs among Asian population is still debateable and our study has certain limitations including non-availability of homogenise reported studies from Asian sub-continents especially central Asia, western Asia and even from south and south east Asia demand large scale collaborative research culture to standardize HPV led HNSCCs aetiology. Beside very potential outcomes, our review has certain limitations including a significant level of heterogeneity in comprised studies, Publication year, variable number of patients, specimen type and HPV detection methods. Similarly, the possibility of confounder cannot be ignoring, because some studies evaluated more then one type of HPV sub-genotype. while an included study detected HPV-16 genotype only as well.

In conclusion, highest priority should be given to initiate homogeneity cancer research programs among Asian countries especially; Afghanistan, Iraq, Nepal and Yemen to assess the tumour positivity rates of HPV in HNSCCs. While in countries like Pakistan, India, Bangladesh, Thailand, North Korea, Iran, Japan and Turkey more collaborative research is needed to standardize prevalence of HPV associated HNSCCs across Asian Continent.

\section{Conflict of Interest}

Nil.

\section{Abbreviations}

PCR, Polymerase chain reaction; ISH, in-situ-hybridizations; ELIZA, Enzyme linked immunosorbent assay; HPV, human papilloma virus; HNC, head and neck cancer; CNS, Central Nervous System.

\section{References}

Abogunrin S, Tanna GLD, Keeping S, Carroll Sand Iheanacho I (2014). Prevalence of human papillomavirus in head and neck cancers in European populations: a meta-analysis. BMC Cancer, 14, 968.
Adnan Ali, Awan SM, Atif MS, Ali S, Mirza N (2018). Correlation of human papillomavirus infection and clinical parameters with five-year survival in oral squamous cell carcinoma. J Laryngol Otol, 132, 628-35.

Adnan Ali, Mirza SM, Ahmad Y, Zahid Z, Enam SA (2018). Human Papillomavirus and human cytomegalovirus infection and association with prognosis in primary glioblastoma patients of Pakistan. World Neurosurg, 121, 931-39.

Akhtar M, Ali L, Hassan Z, Khan I (2013). Association of Human Papilloma virus infection and oral squamous cell carcinoma in Bangladesh. J Health Popul Nutr, 1, 65-69

Asvadi Kermani I, Seifi SH, Dolatkhah R, et al (2012). Human Papilloma virus in head and neck squamous cell cancer. Iran J Cancer Prev, 5, 21-6.

Baig S, Lucky MH, Qamar A, et al (2012). Human papilloma virus and oral lesions in gutka eating subjects in Karachi. J Coll Physicians Surg Pak, 22, 135-8.

Bhurgri Y, Bhurgri A, Usman A, et al (2006). Epidemiological review of head and neck cancers in Karachi. Asian Pac $J$ Cancer Prev, 7, 195-200.

Bozdayi G, Kemaloglu Y, Ekinci O, et al (2009). Role of human papillomavirus in the clinical and histopathologic features of laryngeal and hypopharyngeal cancers. J Otolaryngol Head Neck Surg, 38, 119-25.

Chaturvedi AK, Engels EA, Pfeiffer RM, et al (2011). Human papillomavirus and rising oropharyngeal cancer incidence in the United States. J Clin Oncol, 29, 4294-4301.

Chen YJ, Chang JT, Liao CT, et al (2008). Head and neck cancer in the betel quid chewing area: recent advances in molecular carcinogenesis. Cancer Sci, 99, 1507-14.

Chuang SC, Jenab M, Heck JE, et al (2012). Diet and the risk of head and neck cancer: a pooled analysis in the INHANCE consortium. Cancer Causes Control, 23, 69-88.

De Feo E, Rowell J, Cadoni G, et al (2010). A case-control study on the effect of apoliprotein E genotype on head and neck cancer risk. Cancer Epidemiol Biomarkers Prev, 19, 2839-46.

Faheem A (2007). Cancer registration in Pakistan: contemporary. Asian Pac J Cancer Prev, 8, 452-6.

Ferlay J, Shin HR, Bray F, et al (2010). Estimates of worldwide burden of cancer in 2008: GLOBOCAN 2008. Int J Cancer, 127, 2893-2917.

Gheit T, Anantharaman D, Holzinger D, et al (2017), Role of mucosal high-risk human papillomavirus types in head and neck cancers in central India. Int J Cancer, 141, 143-51.

Gillison ML, Broutian T, Pickard RK, et al (2012). Prevalence of oral HPV infection in the United States, 2009-2010. JAMA, 307, 693-703.

Gunasekera SK, Perera KA, Fernado C, Udagama PV (2015). A shifting paradigm in the etiology of oral and pharyngeal cancer in Sri Lanka: a case-control study providing serologic evidence for the role of oncogenic HPV types 16 and 18 . Infect Agents Cancer, 10, 12.

Ha PK, Chang SS, Glazer CA, Califano JA, Sidransky D (2009). Molecular techniques and genetic alterations in head and neck cancer. Oral Oncol, 45, 335-9.

Hafed L, Farag H, Shaker O, El-Rouby D (2012). Is human papilloma virus associated with salivary gland neoplasms? An in situ-hybridization study. Arch Oral Biol, 57, 1194-9.

Hanif M, Zaidi P, Kamal S, Hameed A (2009). Institution-based cancer incidence in a local population in Pakistan: nine-year data analysis. Asian Pac J Cancer Prev, 10, 227-30.

Hashibe M, Brennan P, Chuang SC, et al (2009). Interaction between tobacco and alcohol use and the risk of head and neck cancer: pooled analysis in the International Head and Neck Cancer Epidemiology Consortium. Cancer Epidemiol 
Biomarkers Prev, 18, 541-50.

Howlader N, Noone A, Krapcho M, et al (2013). SEER Cancer Stat Rev, 2013, 1975-2011.

Jalouli J, Jalouli MM, Sapkota D, et al (2012). Human papilloma virus, herpes simplex virus and Epstein Barr virus in oral squamous cell carcinoma from eight different countries. Anticancer Res, 32, 571-80.

Kerishnan PJ, Gopinath SC B, Kai SB, et al (2016). Detection of Human Papillomavirus 16-specific IgG and IgM antibodies in patient sera: A potential indicator of oral squamous cell carcinoma risk factor. Int J Med Sci, 13, 424-31.

Khovidhunkit SO, Buajeeb W, Sanguansin S, Poomsawat S, Weerapradist W (2008). Detection of human papillomavirus in oral squamous cell carcinoma, leukoplakia and lichen planus in Thai patients. Asian Pac J Cancer Prev, 9, 771-5.

Kreimer AR, Clifford GM, Boyle P, Franceschi S (2005). Human papillomavirus types in head and neck squamous cell carcinomas worldwide a systematic review. Cancer Epidemiol Biomarkers Prev, 14, 467-75.

Lee L-A, Huang C-G, Liao C-T, et al (2012). Human Papillomavirus-16 infection in advanced oral cavity cancer patients is related to an increased risk of distant metastases and poor survival. $J$ Pone, 7, 406-7.

Lee SY, Cho NH, Choi EC, et al (2010). Relevance of human papilloma virus (HPV) infection to carcinogenesis of oral tongue cancer. Int J Oral Maxillofac Surg, 39, 678-83.

Leemans CR, Braakhuis BJ, Brakenhoff RH (2011). The molecular biology of head and neck cancer. Nat Rev Cancer, 11, 9-22.

Liebertz DJ, Lechner MG, Masood R, et al (2010). Establishment and characterization of a novel head and neck squamous cell carcinoma cell line USC-HN1. Head Neck Oncol, $2,5$.

Luo CW, Roan CH, Liu CJ (2007). Human papilloma viruses in oral squamous cell carcinoma and precancerous lesions detected by PCR-based genechip array. Int J Oral Maxillofac Surg, 36, 153-8.

Mansour A, Ali M, Helmy H, Kassim S (2012). Human papillomavirus-16 (HPV-16) infection association with CIAP-2 expression in head and neck cancer. Med Oncol, 29, 2459-65.

Maruyama H, Yasui T, Fujiwara TI, et al (2014). Human papillomavirus and p53 mutations in head and neck squamous cell carcinoma among Japanese population. Cancer Sci, 105, 409-17.

McKay JD, Truong T, Gaborieau V, et al (2011). A genome-wide association study of upper aerodigestive tract cancers conducted within the INHANCE consortium. PLoS Genet, 7, e1001333.

Mujtaba H, Wang Y, Duan Y, et al (2018). Human papillomavirus in tonsillectomy specimen from China and Pakistan- Prevalence and genotype distribution. Pathol Res Pract, 214, 1713-8.

Nasman A, Attner P, Hammarstedt L, et al (2009). Incidence of human papillomavirus (HPV) positive tonsillar carcinoma in Stockholm, Sweden: an epidemic of viral-induced carcinoma. Int J Cancer, 125, 362-6.

Nikakhlagh S, Saki N, Shoar MH, Sartipipor A, Saki S (2012). Incidence of etiologic factors in squamous cell carcinoma of head and neck in Ahvaz. Iran J Otorhinolaryngol, 24, 67.

Office for National Statistics (2006). Cancer Statistics registrations. Registrations of cancer diagnosed in England. (www.statistics.gov.uk/statbase/Product. asp? vlnk=8843\&More=N). SeriesMB1 no.37. 2009.

Pai SI, Westra WH (2009). Molecular pathology of head and neck cancer: implications for diagnosis, prognosis, and treatment. Annual review of pathology mechanisms of disease. Palo Alto: Annual Reviews, pp 49-70.
Burden of HPV-Subtypes Associated HNSCC in Asian Continent

Ryoo NK, Kim JE, Choung HK, et al (2013). Human Papilloma virus in Retinoblastoma tissues from Korean Patients. Korean J Ophthalmol, 27, 368-371.

Seifi S, Asvadi Kermani I, Dolatkhah R, et al (2013). Prevalence of oral human papilloma virus in healthy individuals in East Azerbaijan province of Iran. Iran J Public Health, 42, 79-85.

Soo Yee Tan L, Petersson F, Ker L, et al (2016). High-risk HPV genotypes and P16INK4a expression in a cohort of head and neck squamous cell carcinoma patients in Singapore. Oncotarget, 7.

Syrjanen K, Syrjanen S, Lamberg M, Pyrhonen S, Nuutinen J (1983). Morphological and immunohistochemical evidence suggesting human papillomavirus (HPV) involvement in oral squamous cell carcinogenesis. Int J Oral Surg, 12, 418-24.

Syrjanen K, Vayrynen M, Castren O, et al (1983). Morphological and immunohistochemical evidence of human papilloma virus (HPV) involvement in the dysplastic lesions of the uterine cervix. Int J Gynaecol Obstet, 21, 261-9.

Syrjanen KJ, Syrjanen SM, Lamberg MA, Pyrhonen S (1983). Human papillomavirus (HPV) involvement in squamous cell lesions of the oral cavity. Proc Finn Dent Soc, 79, 1-8.

Termine N, Panzarella V, Falaschini S, et al (2008). HPV in oral squamous cell carcinoma vs head and neck squamous cell carcinoma biopsies: a meta-analysis (1988-2007). Ann Oncol, 19, 1681-90.

Westra W (2009). The changing face of head and neck cancer in the 21st century: the impact of HPV on the epidemiology and pathology of oral cancer. Head Neck Pathol, 3, 78-81.

Yoshizaki T, Endo K, Ren QC, et al (2007). Oncogenic role of Epstein-Barr virus-encoded small RNAs (EBERs) in nasopharyngeal carcinoma. Auris Nasus Larynx, 34, 73-8.

Zhang H, Zhang Y, Zhao H, et al (2016). HPV infection and prognostic factors of tongue squamous cell carcinoma in different ethnic groups from geographically closed cohort in Xinjiang, China. Hindawi Publishing Corporation Biochemistry Research International. 5 pages.

Zil-E R, Baig S, Zaman U, Lucky MH (2018). Human papilloma virus 16/18: Fabricator of trouble in oral squamous cell carcinoma. Int J Infect Dis, 69, 115 - 9.

Zur HH (2009). Papillomaviruses in the causation of human cancers - a brief historical account. Virology, 2, 260-5.

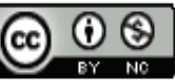

This work is licensed under a Creative Commons AttributionNon Commercial 4.0 International License. 